\title{
Analysis of Types, Sources of Errors and Misconceptions in South African Algebra Cognition
}

\author{
Philile Nobuhle Mathaba ${ }^{1}$, Anass Bayaga, ${ }^{2, *}$ \\ ${ }^{1}$ Department of Mathematics, Science \& Technology Education, Faculty of Education, University of Zululand, South Africa \\ ${ }^{2}$ Senior Secondary Education, Faculty of Education, Nelson Mandela University, Port Elizabeth, South Africa
}

Received January 12, 2021; Revised March 10, 2021; Accepted March 23, 2021

\begin{abstract}
Cite This Paper in the following Citation Styles
(a): [1] Philile Nobuhle Mathaba, Anass Bayaga, "Analysis of Types and Sources of Errors and Misconceptions in South African Algebra Cognition," Universal Journal of Educational Research, Vol. 9, No. 5, pp. 928 - 937, 2021. DOI: 10.13189/ujer.2021.090505.
\end{abstract}

(b): Philile Nobuhle Mathaba, Anass Bayaga (2021). Analysis of Types and Sources of Errors and Misconceptions in South African Algebra Cognition. Universal Journal of Educational Research, 9(5), 928 - 937. DOI: 10.13189/ujer.2021.090505.

Copyright $\odot 2021$ by authors, all rights reserved. Authors agree that this article remains permanently open access under the terms of the Creative Commons Attribution License 4.0 International License

\begin{abstract}
Due to the persistent nature of errors and misconceptions, through SOLO model, the current research was aimed at examining the types and the sources of errors and misconceptions committed by Grade 9 learners in Algebra cognition. Thus, in the current research, the model was applied to assess learners' learning outcomes and to classify the value of the response. Through a survey, the sample size for this study was 100 Grade 9 learners in KwaZulu-Natal province of South Africa. In response to the aim of the research, the themes comprised, algebraic fractions, graphs, expressions and equations, words problems. The results revealed that possible sources were lack of conceptual and procedural knowledge, a lack of factual knowledge, lack of connection between new knowledge and old knowledge, lack of interpretation, errors caused by translation. The major conclusion because of the SOLO theory revealed the level of thinking, indicating both one-structure and many-structures only in equations and expressions involving translation of equation to table and table to the graph. The practical implication is positioned on the need to improve understanding the sources of errors, classified as a lack of conceptual and procedural knowledge; lack of factual knowledge; lack of connection between new knowledge and old knowledge, lack of interpretation, inattentiveness and failure to read and understand; errors caused by translation. The theory applied revealed the need to emphasize other level of thinking as well as sources of errors.
\end{abstract}

Keywords Algebra, Cognition, Cognitive Development, Level of Responses, SOLO Model

\section{Introduction: Situation in South Africa}

The need for the current research was based primarily on the persistent nature of examining the types and the sources of errors and misconceptions committed by Grade 9 learners in Algebra cognition [1,2]. As Chimoni and Pitta-Pantazi [2] lament, even though various studies via different theories have investigated errors and misconceptions, however, a challenge that still remains unresolved is the cognitive development, and level of responses of Algebra cognition via structure of observed learning outcomes (SOLO) (discussed in detailed under theoretical framework section). In response to the challenge, the analyses of the current study are guided by, but not exclusively on algebraic thinking $[2,3]$. We examine recommendation of how learners should organise their knowledge, procedures and concepts $[4,6]$. In view of the objective of the study too, we position the study upon the work of SOLO theory [7]. Based on the SOLO theory, we then build upon a classification of errors and misconceptions in order to develop the methodology leading to the analysis and consequently the conclusion of the research. 


\section{Related Work and Development of Research Question}

As a result of the persistent nature of errors and misconceptions, there is no single accepted definition for errors or misconceptions $[3,6,8]$. The standard ones as adopted below come with some variations $[3,6,8]$. Mulungye, O'Connor and Ndethiu, for instance, are of the opinion that errors "are mistakes in the process of solving a mathematical problem algorithmically, procedurally or by any other method" [8]. Others, on the other hand, claim that algebraic learning built purely on procedural skills without considering conceptual understanding could lead to errors and misconceptions [3]. What may be drawn as suggested $[3,8]$ is that both procedural and conceptual knowledge alone as types of knowledge could lead to errors and misconceptions when performing Algebraic operations. Hence, it may be proposed that educators as a source of knowledge must have a way of changing learners' conceptual knowledge and design strategies when dealing with errors and misconceptions among learners. As a result, it is recommended that learners should organise their knowledge, procedures and concepts so that they are able to retrieve the knowledge and apply it $[4,6]$. Consequently, the learner must learn the concepts first and then the procedure follows.

Drawing from the emphasis of previous research too, it is argued that after the learner has learnt the concept, the concept supports the procedure [9]. Accordingly, in support, there is emphasis that the learner is less likely to forget concepts than procedures - this holds for both human behaviours generally and when the learner is learning algebra [5]. Similarly, it is mentioned that procedural and conceptual errors are caused by a learner's lack of knowledge or misunderstanding of the concept itself $[3,10,11]$. Others claim that errors which originate from a lack of meaning are procedural and structural errors [12]. In previous work, it is argued that when learners do not understand the meaning of certain word roots or origins for instance, they do not understand the terms used and misinterpret what the question requires [13]. Accordingly, it is argued further that this is caused by educators' lack of emphasis when teaching factorisation and other concepts [14].

Another troubling notion is the lack of factual knowledge as a source of error in Algebra: There are several debates regarding the causes of error and types of factual knowledge in Algebra [10, 14, 15, 16, 17, 18]. In some research, it is suggested that factual errors occur when a learner lacks factual information, for example, vocabulary, digit identification and place value identification $[10,11,16]$. For instance, in fractions and factorisations, learners do not have an understanding of the meaning of terms like numerator, denominator, most significant common factor, least common multiple or circumference. Some do not know mathematical formulae, for example, the area of a square or a perimeter $[3,8,19$, $20,21,22]$. In consequence, when learners lack information on or understanding of the concept itself in Algebra, this would result in errors, such as a failure to recognize formulas, consequently leading to the wrong solution or mishandling operation signs that constitute the basics of mathematical Algebra. Many studies on error analysis in Algebra have included equations and expressions, for instance the works exploring the thinking underlying Grade 9 learner errors in introductory Algebra $[19,20,23]$. In essence, what may be drawn from the studies is that various aspects contribute to learners' errors, including task instructions, new knowledge, ignoring the letters, and replacing letters with numeric values [19, 20, 23].

However, it is further recommended that by pointing out to teachers the types of error that is committed by learners in our classes, teachers may be assisted to observe those errors and address the sources of errors and misconceptions, as well as design new strategies for overcoming those errors [20]. A study focused on algebraic graphs and consequently concluded that learners have difficulties working with algebraic graphs [20]. The type of errors found was related to coordinates, intercepts, domain and range, asymptotes, and identification, drawing and function errors. In the study regarding the sources of errors and misconceptions in word problems, for instance, the results revealed; lack of vocabulary, and symbolic and metacognitive skills [18]. For others too, the primary cause of many learners committing implementation errors is a lack of mathematical knowledge $[15,31]$. A potential solution offered is that in the process of conflicts between new knowledge and existing knowledge the logic is to wait for restructured schema to accept or connect in order to work and produce correct solutions and hence the need for the current study [22, 25]. Thus, the errors and misconceptions will only be corrected if learners are able to revise old concepts before learning a new concept.

\subsection{Research Question}

Based on the contestations so far and unrelenting nature of errors and misconceptions, the research question is; what are the types and the sources of errors and committed by Grade 9 learners in Algebra learning?

\subsection{Theoretical Framework: SOLO Model and Koch Error Analysis}

Building on both the research question as well as the previous works, the current study adopted three structures of learner understanding based structure of observed learning outcomes (SOLO) [7, 26, 27]. According to the SOLO model, a learner's response depends on two structures which, in the current case, were cognitive development and levels of response. In this study, the SOLO model was also used to examine levels of thinking 
in the causes of errors and misconceptions among Grade 9 learners in Algebra, to explore the possible sources of errors and misconceptions in Algebra and to identify strategies for avoiding error and misconceptions when learning Algebra.

The choice of the model was also intended to contribute to our understanding of the sources of errors and misconceptions, as well as the strategies for avoiding errors and misconceptions in the senior phase. In previous work, it is argued that the level of structures should be reduced to three, namely, uni-structural, multi-structural, and relational [26]. The structures adopted for the current study took the form of one structure, many structures and relational. In other study, the SOLO model was used to revise and combine items which were designed in such a way that any super item that presents a correct response to an answer indicates thinking ability [26]. For the current study too, the SOLO model focused on the thinking levels of Grade 9 learners when they respond to the questions relating to Algebra, in which case the analysis depended mostly on the learners' responses.

It is important to recognise, however, that when Biggs and Collis developed SOLO theory, there were five structural levels: 1) pre-structure level, meaning no response (no thought); 2) one-structure level meaning one response (little thinking); 3) many-structure level (more thought) meaning that most responses are related to the answer; 4) relational level (much thought) meaning all correct answers; and 5) extra-extended level, meaning exceptional response. For the current study, the researchers excluded two levels, namely, pre-structure (no idea) and extra extended (adequate idea), because the examination was based on learners' types of error committed and the misconceptions learners displayed when they solving Algebra problems, sources of those errors and misconceptions, as well as strategies for avoiding errors and misconceptions in the senior phase. For the current study, the levels of thinking were examined when learners responded to Algebra questions such as equations with fractions, word problems, and translation from an equation to a table or graph.

Koch error analysis was also used in order to complement the SOLO model as suggested [4, 10, 15, 24]. Essentially, Koch error analysis is the process of classifying errors into five types, namely, careless, computation, precision, problem-solving and unpreparedness. The current study used these classifications to describe the types of error found in Grade 9 algebra. For instance, research explains that careless errors occur when learners write down the wrong numbers and do not follow mathematical procedures or directions for what is expected in the answer [28]. It is also argued that the learner fails to pay attention during the lesson perhaps as a result of tiredness. It is further, computational errors are calculations that may be committed wrongly in a mathematical problem when the learner works with operational signs [28]. It is additionally claimed that learners commit errors when working with operational signs, as they misuse addition sign, subtraction, multiplication, and division sign [28]. The current study is also guided by the fact that previous work explains that in precision errors, learners reveal confusion when solving concepts, untidiness, dropping signs and forgetting signs when calculating either addition or subtraction [28]. In addition, other units may disappear - this could be either a variable or a number - and a lack of labelling and notation may also be a problem. As a guide to the current study, it is explained that learners fail to follow proper mathematical rules [28]. Moreover, some do not complete the required steps. In regard to unpreparedness, the current study was guided by claim that this involves the learner not finishing mathematical problems for some reason, for instance, failure to seek help; lack of formative assessment such as free quizzes or quick checks; and lack of corrections on the work [28].

\section{Methodology}

\section{General Background}

In the current study, survey research was aimed at gathering data from 100 Grade 9 learners at schools in the King Cetshwayo District by directing an Algebra test counting 50 marks based on the research question. The question was used to identify the types and sources of errors and misconceptions that Grade 9 learners commit when doing Algebra and the strategies used to avoid these errors and misconceptions. However, methodologically, the research employed quantitative and qualitative data in order to conjointly corroborate the study's results - thus, the current study used mixed methodology or mixed data approach as further described in participants' and instrumentations' section. Consequently, the principle upon which mixed data was drawn into the current research was precisely to collect, analyze, and "mix" both quantitative (through descriptive statistics in this scenario) and qualitative data (through textual analysis in this study) in a single study to understand the research problem.

\section{Participants and instrumentation}

The test comprised four questions which were based on Algebra. Question one covered algebraic fractions, question two graphs, tables, expressions and equations, question three words problems, and question four on equations and expressions related to the concept of ratio, height, length and area. The test counted out of 50. Part One: The researchers requested the sampled learners to write the test in order to identify the types of error committed and misconceptions displayed by Grade 9 learners and the sources of these when solving Algebra problems. Part two: Part two of the research was carried out in the same five schools and the same learners were 
used for interview purposes. In order to compare the findings, six learners per school (giving a total of 30) were selected for the focus group interview. Learners answered the questions orally, and the information was recorded using pen and paper (participant observation). Focus group interviews- from five schools, six learners were chosen per school. Thus the 100 Grade 9 learners were sampled as only 20 learners from each school $(5 \times 20)$ were selected to write the 50-mark test (which formed the quantitative part of the study). In addition, six learners were selected for focus group interviews (which formed the qualitative part of the study). Additionally, the researchers employed two different theoretical frameworks - Koch's theory of error analysis and the SOLO model to address the three research questions as guided by descriptive statistics.

\section{Sample selection}

Choosing appropriate sample size for a qualitative study, while is evolving as conceptual debate as well as practical uncertainty, the current study's researchers recognise number of factors for the small sample size. The sample size for this study was 100 Grade 9 learners ranging in age from 13 to 16 years from five secondary schools in the King Cetshwayo District of the KwaZulu-Natal province in South Africa. Each class comprised of 20 learners. One reason as suggested by researchers [32], for a small sample, particularly in qualitative study tend to; (1) support the depth of case-oriented analysis, which is central to the present form of inquiry. Keenly, it is recommended that (2) while it is important to have sample size large to permit the evolving of a 'new and richly textured understanding' of ideas, but equally small sample size as much as necessary is needed such that 'deep, case-oriented analysis' is not excluded. Last (3), researchers [32] suggest that given more and functional or useable data being collected from respondents, then, fewer participants conversely are required. These three supporting factors, motivated for the small sample size for the current study.

\section{Data and analysis}

Thematic content analysis used in the study focused on the sources of error, namely, test questions, focus group interviews and the literature review to answer the research questions: What type of errors and misconceptions do Grade 9 learners display in simplifying Algebra? Moreover, what are the sources of errors and misconceptions of Algebra expression? In order to ensure validity, the test was moderated by three teachers (moderated by colleagues) with more than five years' working experience in Mathematics in Grades 8 to 12 . Approval from the five schools was also obtained to conduct research in the schools. Informed consent of principals and parents/guardians was obtained using relevant documentation.

\section{Results}

Built upon the research question, the current section presents' both findings regarding the quantitative (test) and the qualitative (focus group interviews) responses. Table 1 indicates the number of learners who responded and the nature of their responses, including those who responded correctly. Some incorrect responses are also indicated as the performance in the task that was given. Recall that the tasks were based on Grade 9 Algebra and included graphs, tables, equations, expressions, rectangular prism (surface area) and the right-angled triangular prism (perimeter, area etc.).

Interpretation of data pertaining to question 1 (test): Question 1 (as seen in Table 1) was divided into four questions as 1.1, 1.2, 1.3 and 1.4 and was based on equations with fractions (common fractions). Analysis of the question subsequently revealed that learners experience problems in solving algebraic fractions. Particularly, the learners' responses were classified as either correct, incorrect or no response. In the test, there were no correct $(0 \%)$ responses to 1.1 . Most $(82 \%)$ respondents gave an incorrect answer and a few (18\%) did not respond at all. In question 1.2, there were no correct $(0 \%)$ responses, $76 \%$ of responses were incorrect, $24 \%$ gave no response. In question 1.3 (in Table 1), there were no correct responses $(0 \%), 80 \%$ gave an incorrect response and $20 \%$ gave no response. In the last question in question 1 , that is, 1.4 , no correct $(0 \%)$ responses were given, $86 \%$ were incorrect and $14 \%$ gave no response. The learners' performance (indicated by percentages) in questions 1.1 to 1.4 indicate that learners struggled to solve algebraic fractions. The low performance (see Table 1) indicates that Grade 9 learners commit errors and hold misconceptions when solving fractions. The types of error and misconception in algebraic fractions were analysed according to Koch error analysis, with the errors being categorised as either careless, precision, problem-solving, computation or preparedness, as discussed in the theoretical framework. 
Table 1. Data on learner performance in the quantitative investigation

\begin{tabular}{|c|c|c|c|c|c|}
\hline \multirow[b]{2}{*}{ Question } & \multicolumn{4}{|c|}{ Number } & \multirow{2}{*}{$\begin{array}{l}\text { Explanation based on the number of } \\
\text { learners and the number of responses }\end{array}$} \\
\hline & wrote & $\begin{array}{c}\text { correct } \\
\text { response }\end{array}$ & $\begin{array}{c}\text { incorrect } \\
\text { response }\end{array}$ & $\begin{array}{c}\text { No of } \\
\text { response }\end{array}$ & \\
\hline$\frac{5 x}{7 x-7}=\frac{5}{3 x-3}$ & 100 & 0 & 82 & 18 & $\begin{array}{l}\text { In this question, there was no correct } \\
\text { response. Most respondents gave an } \\
\text { incorrect answer. A few did not respond. }\end{array}$ \\
\hline$\frac{1}{x}-\frac{1}{x+4}=\frac{-4}{x^{2}-16}$ & 100 & 0 & 76 & 24 & $\begin{array}{l}\text { No correct response. Most respondents } \\
\text { gave an incorrect answer. A few did not } \\
\text { respond. }\end{array}$ \\
\hline$\frac{1.3}{x-1}+\frac{x}{2 x+1}=\frac{3}{(2 x+1)(x-1)}$ & 100 & 0 & 80 & 20 & $\begin{array}{l}\text { No correct response. Most respondents } \\
\text { got an incorrect answer. A few did not } \\
\text { respond. }\end{array}$ \\
\hline$\frac{1.4}{x^{2}-1}+\frac{2}{x+1}=\frac{1}{x-1}$ & 100 & 0 & 86 & 14 & $\begin{array}{l}\text { No correct response. Most respondents } \\
\text { gave an incorrect answer. A few did not } \\
\text { respond. }\end{array}$ \\
\hline \multicolumn{6}{|l|}{ Question 2} \\
\hline $\begin{array}{l}\text { 2.1.1 Write a set of ordered pairs } \\
\text { in the form of a values in the table } \\
\text { values relationship depicted by } \\
\text { graph. }\end{array}$ & 100 & 61 & 39 & 0 & $\begin{array}{l}\text { Many learners got this question right. } \\
\text { They simply drew a table and set up both } \\
\text { values correctly and drew a graph. A few } \\
\text { learners drew the graph incorrectly from } \\
\text { the correct table. }\end{array}$ \\
\hline $\begin{array}{l}2.1 .2 \\
\text { Determine equation of the graph }\end{array}$ & 100 & 2 & 89 & 9 & $\begin{array}{l}\text { Many learners responded incorrectly. } \\
\text { Many errors and misconceptions were } \\
\text { found in this question. Some learners did } \\
\text { not respond at all. }\end{array}$ \\
\hline $\begin{array}{l}2.1 .3 \\
\text { If } x=6 \text {, determine the output }\end{array}$ & 100 & 2 & 83 & 15 & $\begin{array}{l}\text { Many learners responded incorrectly. } \\
\text { Many errors and misconceptions were } \\
\text { found in this question. }\end{array}$ \\
\hline $\begin{array}{l}\text { 2.2 Given equation } y=2^{x+1} \\
\text { 2.2.1 Draw a table of values for } \\
\text { the values of } x=0,1,2,3,4\end{array}$ & 100 & 20 & 25 & 55 & $\begin{array}{l}\text { Many learners did not respond at all to } \\
\text { this question. Some gave the correct } \\
\text { answer and others gave wrong answers. } \\
\text { Errors and misconceptions were found. }\end{array}$ \\
\hline $\begin{array}{l}\text { 2.2.2 Draw an accurate graph for } \\
\text { the relationship generated by an } \\
\text { equation. }\end{array}$ & 100 & 51 & 45 & 04 & $\begin{array}{l}\text { Most learners drew the graph correctly, } \\
\text { but others got it wrong. A few did not } \\
\text { respond. Some errors were found. }\end{array}$ \\
\hline
\end{tabular}

However, the cognitive levels were analysed according to the SOLO model where the levels of thinking are classified based on a structure where one idea corresponds to the one response and many-structures indicates many ideas corresponding to the question and lastly relational, which indicates that all ideas respond to the question (in this instance none obtained). Interpretation of data pertaining to question 2 (test) (see Table 1): Question two was divided into five sub-questions that was based on graphs, equations, expressions and tables. About $61 \%$ of learners gave the correct answer. In this question, they were required to draw a table and set up both values correctly, and then draw its associated graph. Other learners $(39 \%)$ drew the graph incorrectly even though they had the right table and thus responded incorrectly. In 2.1.2, many $(89 \%)$ learners responded incorrectly, with just a few (2\%) responding correctly, while $9 \%$ did not respond at all. In 2.1.3, many (83\%) learners responded incorrectly. In 2.2.1, about half (55\%) of learners did not respond at all in this question, while $20 \%$ of them responded correct, and others responded incorrectly (25\%). In 2.2.2, most learners (51\%) drew the graph correctly, but others (45\%) got it wrong. Few (4\%) learners did not respond at all.

In both 2.1.1 and 2.2.2, as reflected in Table 1, the performance was better compared with other responses in question two (2.1.2 and 2.1.3). This indicates that these learners $(51 \%)$ had attained the skill to draw graphs and to translate from the graph to the table $(61 \%)$, however, in 2.1.1, 39\% did not respond and 2.2.2 (48\%), thus indicating that they lack skills in translating from equations to graphs. These skills involved those relating to computation and substitution from equations. Like the errors in question 1, question 2 was also analysed according to Koch error analysis with errors being classified as careless, precision, computation, problem-solving or preparedness. The cognitive levels were analysed according to the SOLO model. The SOLO structures adopted were one-structure, meaning that one idea revealed in the response; many-structures, meaning many ideas but not all of them correspond with the question as highlighted in the analysis, and lastly relational, which indicates all ideas are responding to the question. 
In addition, error analysis using Koch's procedure was applied as suggested by the research question. The errors and misconceptions committed by Grade 9 learners when solving Algebra problems were analysed using Koch error analysis in terms of careless errors, computation errors, problem-solving errors, precision errors and error caused by unpreparedness. Moreover, as highlighted by researchers $[26,29]$ in the literature, SOLO's structure is useful for analysing learner cognition. However, this study did not consider either pre-structure or extra-extended structures because of the nature of the research questions. The Koch's procedure for error analysis was used to analyse errors in all questions (comprising Algebra equations with fractions) as partly reflected in Table 1. In response to the research question and in accordance with SOLO, learners' responses containing one-structure, many-structures were selected.

The below presents a sample of learners' work, expected response as well as the learner's response. Thereafter, an analysis of the response was followed. Learner 1: (Question 1): Learner Activity No. 1; solve for $\mathrm{x} \frac{5 x}{7 x-7}=\frac{5}{3 x-3}:$ Expected answer: $15 \mathrm{x}^{2}-15=35 \mathrm{x}: 15 \mathrm{x}^{2}$ $-50 \mathrm{x}+35=0: 3 \mathrm{x}^{2}-10 \mathrm{x}+7=0:(3 \mathrm{x}-7)(\mathrm{x}-1)=0$ : $x=\frac{7}{3}$ or $x=1$

Learner 1's response (question 1)

$$
\begin{aligned}
\frac{5 x}{7 x-7}= & \frac{5}{3 x-3}=\frac{5}{7 x^{2}}-7-\left(-\frac{5}{3 x-3}\right)=\frac{5}{3 x-3}\left(\frac{5}{3 x-3}\right)= \\
& \frac{5}{7 x^{2}}+\frac{5}{3 x-4}=0 \text { (incorrect response) }
\end{aligned}
$$

Figure 1. Learner 1's written work showing problem-solving (Koch's theory)

In Figure 1, learner 1 failed to complete all the steps. Another error was shown when the learner mishandled the signs, as revealed by the use of multiplication instead of division, for instance, when the learner computed $(x \div x=$ $\mathrm{x}^{2}$ ). Koch's theory classifies this type of error as a careless error. On the other hand, Makonye (2011) believes that this type of error is usually caused by distraction and is as a consequence, a careless error (Koch's theory). Reference [29] maintains that the learner knows what the problem requires, however they failed to apply the procedural knowledge, which meant the learner ended up with the wrong solution. Nevertheless, in previous review, it was found that learners used addition instead of multiplication [30]. In the current study, the learner used division instead of multiplication. Some maintain such errors are committed because the learner has failed to pay attention during teaching and learning [17]. What could be drawn from previous work is that although the learner would seem to have an idea about how to approach the problem when able to handle variables, nonetheless, failed to handle the sign as a basis of mathematics $\left(\mathrm{x} \div \mathrm{x}=\mathrm{x}^{2}\right)$ in Figure $1[17,29]$.

In response to such errors, the basic suggestion by researchers is that teachers and learners should use the
BODMAS rule to solve such problems $[28,30]$. On the other hand, research [30] maintains that the BODMAS rule is a semiotic intervention which serves as recap support.

In another question related to learner 2, the following was observed.

\section{Learner 2: Learner No. 2 (question 1)}

$$
\begin{gathered}
\frac{5 x}{7 x-7}=\frac{5}{3 x-3}=(5 x-(3 x-3)=5-(7 x-7)=2- \\
3 x=-2-5=-1--5=x= \\
4 \text { (incorrect response) }
\end{gathered}
$$

Figure 2. Learner's written work showing computation error (Koch's theory)

In line with Koch's theory, this error was analysed as a computation error, because the learner failed to operate the sign in the problem. That is learner 2 failed to understand the meaning of brackets, which in fact required the same operation as a multiplication sign. It is suggested that teachers should emphasise the meaning of brackets in an equation or expression. Figure 3, reflecting learner's written work revealed problem-solving error (Koch's theory) as demonstrated in learner activity 2.

Learner activity: $2 \quad \frac{1}{x}-\frac{1}{x+4}=\frac{-4}{x^{2}-16} ; \quad$ Expected answer: $\frac{1(x+4)-1(x)}{x(x+4)}=\frac{-4}{x^{2}-16} ; \frac{x+4-x}{x(x+4)}=\frac{-4}{x^{2}-16} ; 4\left(x^{2}-16\right)=$ $-4\left(\mathrm{x}^{2}+4 \mathrm{x}\right) ; 4 \mathrm{x}^{2}-64=-4 \mathrm{x}^{2}-16 ; 8 \mathrm{x}^{2}+16 \mathrm{x}-64=0 ; \mathrm{x}^{2}+2 \mathrm{x}$ $-8=0$

Learner's response No. 3 (question 1)

$$
\begin{gathered}
\frac{1}{x}-\frac{1}{x-4}=\frac{-4}{x^{2}-16}=\frac{1}{x}-\frac{1}{4 x}=\frac{4}{16 x}=\frac{x}{4 x^{2}} \times \frac{4}{16 x} \\
=\frac{4 x}{64 x} \text { (incorrect response) }
\end{gathered}
$$

Figure 3. Learner's written work showing problem-solving (Koch's theory)

In analysing learner 3's response, it was revealed that the learner (learner 3, Fig. 3) did not follow mathematical rules and procedure due to failure in completing all the steps. As highlighted in the analysis in case 1, the learner does not show an understanding of the concept but instead wrote all the mathematical steps wrong when solving the problem, in effect failed to conceptualise.

What could be drawn from Figure 3 too was that the conjoining errors, as suggested by researchers [19, 20, 22] was revealed in the solution as $\mathrm{x}+4=4 \mathrm{x}$ and $\mathrm{x}^{2}-16=$ 16x. In response to conjoining errors, research [23] revealed that these types of error are caused by a lack of knowledge regarding the concept of algebraic expressions. Furthermore, researchers believe that these errors are caused by interpretation of expressions, for instance, $9 \mathrm{x}+$ 4 ; as add nine times and 4 or as an object $[1,8,19,20,21$, 22].

The conclusion thus reached this far is that it is suggested that teachers need to emphasise the meaning of 
the sign in the expression and the meaning of the number that is bonded with the variable, such that 9 should be multiplied by $\mathrm{x}$. This means that there is no relationship between 9 and 4 to operate the sign in between. As a consequence of such errors too, research [26] suggests that Grade 9 learners should stop overlooking operational signs in the expression as a symbol of joining terms.

In addition to aforementioned errors, cancelling errors as suggested by previous studies [29, 31] appeared in the solution when the learner revealed the line on top, which indicated that $4 \mathrm{x}$ cancelled with another $4 \mathrm{x}$ (as in Figure $3)$. This was due to cancelling without meaning or "senseless cancelling" as characterised by previous work [30]. As suggested too, this involves cancelling similar variables without following procedure.

In response to such errors, research [23] suggests generalisation in order for the learner to understand and recognise the characteristics of the expressions and equations. Another probable solution offered by researchers [29] suggests fusion; wherein the teaching of fractions, learners become familiar with the different structures of equations and fractions. Another sample response from Figure 4: Learner's written work showed problem-solving (Koch's theory)

Learner No. 4: On the same Activity: Learner's response: No. 4 (question)

$$
\frac{1}{x}-\frac{1}{x+4}=\frac{4}{x-16}=\frac{6}{20 x} \text { (incorrect response) }
$$

Figure 4. Learner's written work showing problem-solving (Koch's theory)
Learner 4, as reflected in Figure 4, added both denominators and numerators. This is a common fractional error committed by learners when they are unable to handle variables [23, 29, 32]. It may be deduced from the Figure 4 that the error was caused by a lack of knowledge of the concept itself. As a result, there was poor conceptual and poor procedural knowledge as discussed in the literature by researchers $[1,10,11,32]$. It is important to also recognise that the lack of knowledge leads to poor algebraic problem-solving. As a result, researchers $[10,11]$ claim that procedural and conceptual errors are due to a learner's failure to understand the concept. Researchers mention that this type of error is usually caused by the concept having little meaning to the learner, which leads to procedural errors [4]. Hodgen, Foster, Marks and Brown [4] suggest that learners need to develop or restructure their previous knowledge so that they are able to apply and retrieve knowledge. Additionally, an analysis of the frequency of types of all errors revealed the following; procedural and conceptual, factual knowledge, lack of interpretation, lack of emphasis, and error translation.

\section{Discussion}

As guided by the research question, which sought to investigate the types and the sources of errors and misconceptions committed by Grade 9 learners in Algebra learning. A number of key factors evolved. For instance, there are possible sources of errors thus, types of errors in learners solving Algebra as illustrated by Figure 5 .

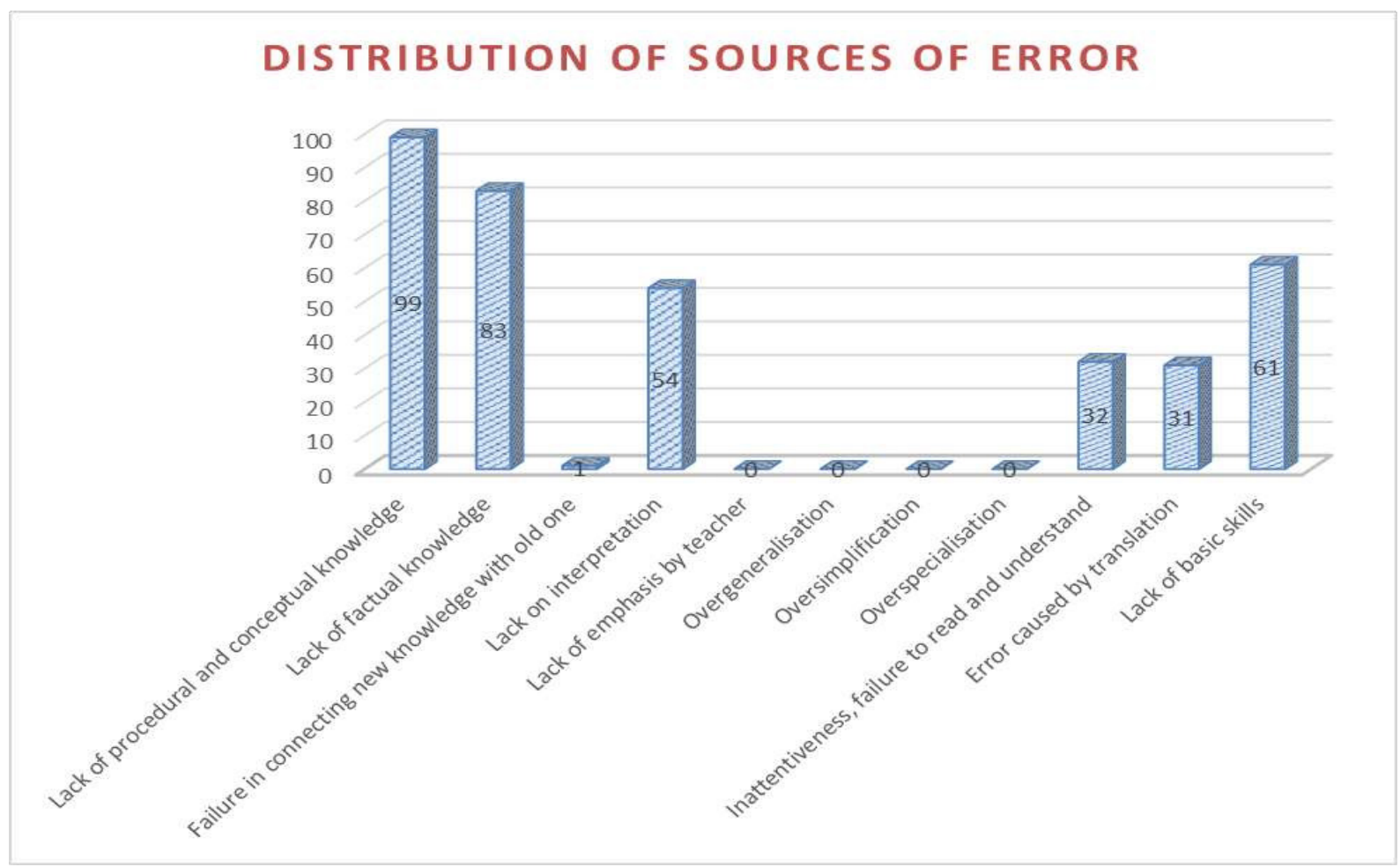

Figure 5. Distribution of errors sources 
Figure 5 presents the distribution of all sources of error. As a consequence of the findings based on the research question and Koch's error analysis as well as the SOLO model, the possible sources of errors included; a lack of conceptual and procedural knowledge (revealed by $99 \%$ of learners), a lack of factual knowledge ( $83 \%$ of learner, lack of connection between new knowledge and old knowledge ( $1 \%$ of learners), lack of interpretation $(54 \%$ of learners), lack of emphasis by the teacher $(0 \%$ of learners), over-generalisation ( $0 \%$ ), over-simplification $(0 \%)$, overspecialisation $(0 \%)$, inattentiveness, failure to read and understand (32\%), errors caused by translation (graph to equation, graph to table, table to graph equation to table and table to equation) (31\%) and lastly, learners' lack of basic skills (61\%). Thus, in the current research, the model was applied as a means to assess learners' learning outcomes and to classify the value of the response, which could be concluded from the structure of the answer as reflected in the mathematical task assigned and the research question. For example, in the following equation, an error was caused by the negative sign. One learner computed $5 x-(3 x-3)$ as $5-(7 x-7)$. In this case, there was no need for negative signs, as the learner was supposed to have removed them: $5 \mathrm{x}-(3 \mathrm{x}-3)=5-(7 \mathrm{x}-$ 7). This occurred because the learner had already inserted a bracket, which accounted for multiplication. Many errors associated with a lack of procedural knowledge were found in the study and could have been avoided, as suggested by authors [1, 4, 27]. For example, some learners used the correct formula, but failed to remove brackets with multiplication, thus revealing a lack of factual information [5]. Some learners too, showed that they had learned the concept of equations and expressions that involve the use of the formula for calculating the area. However, they failed to apply the correct mathematical rules. Using Koch's error analysis, L2 evidenced an error in computation when computing $3 \mathrm{x} \times \mathrm{x}$ as $4 \mathrm{x}$. The error originated from the bracket $3 \mathrm{x}(\mathrm{x}-2)$; only the first term was multiplied and the multiplication of the second term was ignored and replaced with addition signs.

Lack of procedural knowledge: To avoid the sources of errors and errors resulting from a lack of procedural knowledge, learners need to develop and organise their procedures $[1,11]$. However, the teacher, as the facilitator, should plan this development and attempt to change their beliefs and perceptions to avoid rooting these errors in their minds. Research postulates that altering the learners' conceptual framework is the best solution for overcoming and correcting errors when learning Algebra [6].

Researchers $[3,6,9,14,17]$ have reviewed studies on the effect of concrete representational abstract (CRA). The CRA is the teaching strategy that helps teachers to teach learners fraction in a manner so that they can easily understand them. Other researchers [14] indicate that the use of CRA is best for the effective teaching of Mathematics. Research [7] supports the notion that in teaching learners', CRA encourages or motivates learners who have difficulties with numbers. In a review by other research [6], it is also argued that the use of CRA in solving equations by using the inverse operation, is best for instructional learning of mathematics. Research reveals that the CRA may be effective for learners with disabilities [5]. This indicates that the use of CRA is highly suitable for teaching Algebra in secondary schools to learners with difficulties. Research [10] recommends the CRA method of teaching when teaching fractions and claims that this method is useful when teaching learners with difficulties, as learners are encouraged and motivated. Theoretical support for such an idea from Biggs and Collis [7] suggests that the use of CRA in solving equations using inverse operations is the best means of instruction. Teachers are advised to use CRA when teaching fractions so that Grade 9 learners avoid errors when trying to solve Algebra problems.

Careless errors: About $13 \%$ of the learners were found to have made careless errors in this study. Thus, in solving algebraic fractions, learners' results also revealed careless errors. The learners' responses indicated that they misused operational signs, and there was no evidence to show that learners were able to solve the given tasks in each step, as they wrote down numbers incorrectly, and used operational signs incorrectly; for example, one learner computed $x \div x=x^{2}$. As stated by Khanyile [22], careless errors arise due to the incorrect use of operational signs. The errors may also occur as a result of careless use of the division sign as a multiplication sign, using the addition sign as a multiplication sign, and so forth. Others [22, 25] believe that these careless errors may be due to lack of basic algebraic knowledge. Learner 4, for example, failed to divide, as directed to do so by the division sign, instead of carrying out multiplication.

Problem-solving errors: Problem-solving errors were the most common errors found in the learners' scripts. Problem-solving errors occur when learners fail to follow the directions for solving mathematical problems. In this study, $86 \%$ of learners made such errors. The source of this type of error is a lack of conceptual and procedural knowledge, which results in learners failing to solve the problem. All mathematical steps in the problem were wrong because the learners lacked conceptual knowledge and procedural knowledge [1, 3, 22, 27, 28]. In some of the questions, for instance, in which learners were required to solve equations containing fractions, one of the learners was found to be adding numerators and adding denominators. Other researchers [27, 28, 29, 31] observed a similar type of error and believed that these errors are caused by the incorrect treatment of variables, where a learner fails to perform or solve a mathematical problem. The possible sources of the errors are identified in the literature by various researchers $[29,30,31]$ as a lack of conceptual and procedural knowledge.

Koch [27] classifies a problem-solving error as one 
where the learner ignores or fails to follow analytical procedures and rules. Here, learners' test results revealed evidence of poor reasoning or failure to conceptualise. Another error type is one that is the result of a failure to follow adequate algebraic rules; for instance, a conjoining error $[1,23,25,27,30,31]$. For instance, learners revealed conjoining errors in this study by displaying the joining of terms using the plus sign as a joiner $\left(2 x^{2}+3=\right.$ $\left.5 x^{2}=10 x\right)$. As stated by Gumpo [18], the source of this type of error is learners' inability to translate between the numbers and variables. Learners' failure to interpret word problems and translate them to equations indicates a lack of conceptual and procedural knowledge.

Other problem-solving errors included cancelling without following the procedure, which was caused by a lack of knowledge of both concepts and procedures. Makonye and Khanyile [28] identify a cancellation error as a different type of error and mention that learners cancel 'willy-nilly' without following mathematical rules. When solving algebraic tasks, there are rules for cancellation. Therefore, cancellation errors are caused by a lack of conceptual and procedural knowledge.

Also, Egodawatte and Stoilescu [1] believe that a lack of conceptual understanding of its meaning causes errors. Conclusively and to resolve this type of error among learners, Hodgen et al. [4] recommend that learners need to restructure their existing knowledge to prepare themselves for new knowledge, analytical procedures and concepts so that they can retrieve and apply the correct knowledge.

In summary, the SOLO and Koch's error analysis technique revealed the level of thinking, indicating one-structure (equations with fractions, word problems and equations and expressions that include the concept of ratio, height, length, area and perimeter). Many-structures only in equations and expressions involving translation through an equation to table and table to the graph. The sources of errors were classified using literature sources, as a lack of conceptual and procedural knowledge; lack of factual knowledge; lack of connection between new knowledge and old knowledge, lack of interpretation, inattentiveness and failure to read and understand; errors caused by translation.

\section{Conclusions and Future Research}

One major conclusion is that types of error(s) learners display when learning algebra differ in classification. As a consequence, instructors need to identify the sources of errors when teaching Algebra. Beyond the views shared and general conclusion, a specific conclusion and thus implication thereof is that (1) learners' mistakes, blunders, deviations and false ideas are built on incorrectly assumed facts and that they (2) are related to their prior learning of Algebra. However, to adequately address learners' errors, only learning Algebra, based on the contestations thus far was considered for the conceptualisation of error types. Thus, as part of theory and practice of learning Algebra, it is prudent to employ both the SOLO and Koch's error analysis technique to address learners' errors in learning Algebra. It would be far sighted to suggested that this form of conceptualisation addresses all errors, as such, it is recommended that future studies employ SOLO and Koch's error analysis technique in the conceptualisation of other mathematics concepts other than Algebra.

\section{REFERENCES}

[1] Egodawatte, G., \& Stoilescu, D. Grade 11 students' interconnected use of conceptual knowledge, procedural skills, and strategic competence in Algebra: A mixed method study of error analysis. European Journal of Science and Mathematics Education, vol. 3, no 3, pp. 289305, 2015.

[2] Chimoni, M., \& Pitta-Pantazi, D. Parsing the notion of algebraic thinking within a cognitive perspective. Educational Psychology, vol. 37, no. 10, pp. 1186-1205, 2017. Doi.org/10.1080/01443410.2017.1347252.

[3] Egodawatte, G. Secondary school student's misconceptions in algebra. Teaching and Learning Ontario Institute for Studies in Education University of Toronto, Canada. 2011, pp. 34-56.

[4] Hodgen, J., Foster, C., Marks, R., \& Brown, M. Improving mathematics in key stages two and three: Evidence review. London: Education Endowment Foundation. 2018, pp. 45-67.

[5] Schwartz, J. E. A distinction between conceptual knowledge and procedural knowledge. Pearson Allyn Bacon Prentice Hall. Retrieved May 16, 2015, from http://www.education.com/reference/article/distinction-con ceptual-proceduralmath/ (accessed Jun. 1, 2020).

[6] Tweed, A. Addressing student misconceptions (preconceptions) in maths and science classrooms Session 3. Thinking Conference \& Learning, Hawker Brownlow Education. 2014, pp. 67-78.

[7] Biggs, J., \& Collis, K. The Structure of Observed Learning Outcomes (SOLO) taxonomy. Teaching \& Learning Support. 1982, pp. 56-78.

[8] Mulungye, M. M., O'Connor, M., \& Ndethiu, S. Sources of student errors and misconceptions in Algebra and effectiveness of classroom practice remediation in Machakos County-Kenya. Journal of Education and Practice, vol. 7, no. 10, pp. 31-33, 2016.

[9] National Council of Teachers of Mathematics. Principles to action: Ensuring mathematical success for all. VA, Reston. 2014, pp. 12-34.

[10] Fisher, D., \& Frey, N. Making time for feedback. Educational Leadership, vol. 70, no. 1, pp. 42-47, 2012.

[11] Riccomini, P. J. Identifying and using error patterns to inform instruction for student struggling in mathematics, 
VA, Webinar series, Region, 2014, pp. 67-78.

[12] Zakaria, E. Analysis of students' error in learning of quadratic equations. International Education Studies, vol. 3, no. 3 , pp. 105-110. DOI: 10.5539/ies.v3n3p105.

[13] Adu-Gyamfi, K., Stiff, L., and Bosse, M. Lost in translation: Examining translation errors associated with mathematics representations. School Science and Mathematics, vol. 112, no. 3, pp. 159-170, 2012. Doi.org/10.1111/j.1949-8594.201 1.00129.x.

[14] Adu-Gyamfi, K., Bossé, M. J., and Chandler, K. Situating student errors: Linguisticto-Algebra translation errors. International Journal for Mathematics Teaching \& Learning. vol. 1, no. 2, pp. 34-56, 2015.

[15] Brown, J., Skow, K., \& The IRIS Centre. Mathematics: Identifying and Addressing student errors. Retrieved from http://iris.peabody.vanderbilt.Edu/case studies/ics_matherr.pdf (accessed Feb, 4, 2020).

[16] Cooper, H. M. The battle over homework: Common ground for administrators, teachers, and parents. New York, Skyhorse, 2015, pp. 67-89.

[17] Madzorera, A. Investigating challenges that Grade 11 mathematics learners face when translating from word problems to linear algebraic representations (Doctoral dissertation, University of Witwatersrand, Johannesburg), 2015, pp. 45-67

[18] Gumpo, L. Learner thinking about introductory algebra and integers (Unpublished BSc (Hons) research report). University of the Witwatersrand, Johannesburg, 2011, pp. 23-45.

[19] Mashazi, S. Learner's explanations of the errors they make in introductory algebra. Jules High School \& Wits Maths Connect Secondary Project, School of Education, and University of Witwatersrand, 2014, pp. 34-67.

[20] Mdaka, B. R. Learner's errors and misconceptions: Mathematics education. London: HMSO, 2011, pp. 21-34.

[21] Pournara, C., Hodgen, J., Sanders, Y., \& Adler, J. Learners' errors in secondary algebra: insights from tracking a cohort from Grade 9 to Grade 11 on a diagnostic algebra test. Pythagoras, vol. 37, no. 1, pp. 1-10, 2016. Doi.org/10.4102/pythagoras.v37i1.334.

[22] Khanyile, D. W. Resourcing learner errors and misconceptions on Grade 10 fractional equations at a Mathematics clinic, Faculty of Science, University of the Witwatersrand (MSc degree). University of the
Witwatersrand, Johannesburg. 2016, pp. 23-45.

[23] Brijlall, D. \& Ndlovu, Z. High school learners' mental construction during solving optimisation problems in calculus: A South African case study. South African Journal of Education, vol. 33, no. 2, pp. 45-67, 2013. DOI: 10.15700/saje.v33n2a679.

[24] Gardee, A. and Brodie K. A teacher's engagement with learner errors in her Grade 9 mathematics classroom. Pythagoras, vol. 36, no. 2, pp. 1-9, 2015.

[25] Lian, L. H., and Yew, W. T. Assessing algebraic solving ability: A theoretical framework. International Education Studies, vol. 5, no. 6, pp. 177-180, 2012. Doi:10.5539/ies.v5n6p177.

[26] Lucander, H., Bondemark, L., Brown, G., and Knutsson, K. The structure of observed learning outcome (SOLO) taxonomy: A model to promote dental students' learning. European Journal of Dental Education, vol. 14, no. 3, pp. 145-150, 2010. DOI: 10.1111/j.1600-0579.2009.00607.x.

[27] Koch, H. Koch's honours algebra 2 assessment retake contract at Khan Academy. (http://www.khanacademy.org/) ,www.patrickjmt.com,iTunesUniversity, http://www.brightstorm.com/math/ (accessed Aug, , 2020).

[28] Makonye J. P., and Hantibi, N. Exploration of Grade 9 learners' errors on Operations with directed numbers. Mediterranean Journal of Social Sciences, vol. 5, no. 20, pp. 1564-1572, 2014. DOI: 10.5901/mjss.2014.v5n20p1564.

[29] Makonye, J. P. Learner errors in introductory differentiation tasks: A study of learner misconceptions in the National Senior Certificate examinations. The University of Johannesburg, Auckland Park, South Africa. 2011, pp. 45-67.

[30] Sanders, Y. Learners' performance in arithmetic equivalences and linear equations (Doctoral dissertation). 2017, pp. 56-67.

[31] Makonye, J. P. Towards an analytical protocol for learner perturbable concepts in introductory differentiation. The International Journal of Learning, vol. 18, no. 6, pp. 339-56, 2012. Doi.org/10.29333/iejme/6294.

[32] Vasileiou, K., Barnett, J., Thorpe, S. \& Young, T. (2018). Characterising and justifying sample size sufficiency in interview-based studies: systematic analysis of qualitative health research over a 15-year period. BMC Med Res Methodol 18, 148 (2018). https://doi.org/10.1186/s12874-0 18-0594-7 